\title{
4-Methylumbelliferone inhibits ovarian cancer growth by suppressing thymidine phosphorylase expression
}

\author{
Ryosuke Tamura', Yoshihito Yokoyama ${ }^{* *}$, Hidemi Yoshida², Tadaatsu Imaizumi and Hideki Mizunuma'
}

\begin{abstract}
Background: 4-Methylumbelliferone (4-MU), a hyaluronan (HA) synthesis inhibitor, has antitumor activity in cancer cells. However, few studies have focused on its effects on ovarian cancer. The aim of this study was to investigate the effects of 4-MU on ovarian cancer and to elucidate its mechanism of action.

Methods: The HRA human ovarian serous adenocarcinoma cell line was used in this study. The effects of 4-MU on cell proliferation, migration, and invasion were determined by using in vitro assays as well as an in vivo rat peritoneal carcinomatosis model. The expression of HA synthase (HAS), CD44 HA receptor, vascular endothelial growth factor (VEGF), and thymidine phosphorylase (TP) mRNA in HRA cells was analyzed by quantitative reverse transcriptase-polymerase chain reaction (qRT-PCR).

Results: 4-MU administration inhibited the growth of peritoneal tumors and significantly prolonged survival. In vitro experiments showed that 4-MU inhibited HRA cell proliferation in a dose-dependent manner, while it did not affect HRA cell invasion and migration. 4-MU significantly decreased TP mRNA expression in HRA cells. On the other hand, since HAS2, CD44, and VEGF endogenous mRNA expression levels were very low in HRA cells, it was impossible to evaluate the effect of 4-MU treatment.
\end{abstract}

Conclusions: These results suggest that 4-MU exerts its antitumor effect on ovarian cancer through suppressing TP expression.

Keywords: 4-Methylumbelliferone, Ovarian cancer, Peritonitis carcinomatosa, Hymidine phosphorylase, HRA cells

\section{Background}

Epithelial ovarian cancer is the most lethal malignancy in women because it is usually diagnosed at the severe peritonitis carcinomatosa advanced stage of the disease. Epithelial ovarian cancer is the sixth and eighth leading cause of cancer mortality among women in developed and developing countries [1]. The worldwide estimated number of new ovarian cancer cases increased from 137,600 in 1980 to 225,000 in 2008 [1]. There are different strategies for treating advanced ovarian cancer. Cytoreductive surgery followed by adjuvant chemotherapy is commonly recommended as the primary treatment for advanced (stage III/IV) epithelial ovarian cancer.

\footnotetext{
* Correspondence: yokoyama@cc.hirosaki-u.ac.jp

1 Department of Obstetrics and Gynecology, Hirosaki University Graduate

School of Medicine, 5 Zaifu-cho, Hirosaki 036-8562, Japan

Full list of author information is available at the end of the article
}

Alternatively, neo-adjuvant chemotherapy may be selected for patients with bulky stage III/IV tumors for which surgery would be suboptimal. Postoperatively, the combination of a taxane and carboplatin is used as first-line chemotherapy [2]. Moreover, taxanes, carboplatin, cisplatin, liposomal doxorubicin, gemcitabine, etoposide, or topotecanin in combination or as single agents are acceptable as second- or third-line therapies for relapsed disease. Thus, chemotherapy plays an important role in ovarian cancer treatment. However, some patients with advanced ovarian cancer develop chemoresistance, which makes it difficult to prevent the development of peritonitis carcinomatosa, leading to reduced quality of life and a poor prognosis. Since the effects of the available treatments for ovarian cancer are restricted, it is necessary to develop new drugs.

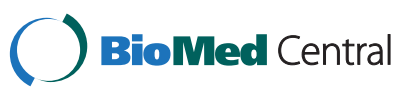

(C) 2014 Tamura et al.; licensee BioMed Central Ltd. This is an Open Access article distributed under the terms of the Creative Commons Attribution License (http://creativecommons.org/licenses/by/4.0), which permits unrestricted use, distribution, and reproduction in any medium, provided the original work is properly credited. The Creative Commons Public Domain Dedication waiver (http://creativecommons.org/publicdomain/zero/1.0/) applies to the data made available in this article, unless otherwise stated. 
Recent clinical trials showed that targeted drugs, such as bevacizumab [3], poly(adenosine diphosphate-ribose) polymerase inhibitors [4], farletuzumab [5], and trabectedin [6], are effective for ovarian cancer treatment and some of them are used clinically. However, because of concerns, including adverse reactions and cost-effectiveness, the clinical advantages of targeted drugs for ovarian cancer treatment remain unclear.

Hyaluronan (HA) is a high-molecular-weight glycosaminoglycan and a major component of the pericellular matrix. HA, which is synthesized by hyaluronan synthase (HAS), regulates multiple cellular functions [7]. The cellular effects of HA are mediated through the CD44 HA receptor [8]. CD44 has also been recently recognized as a cancer stem cell surface marker in several cancer types $[9,10]$, and CD44 expression in cancer cells promoted bone metastasis by enhancing tumorigenicity, cell migration and invasion, and HA production [11]. 4-Methylumbelliferone (4-MU) is an HA synthesis inhibitor [7]. 4-MU blocks HA synthesis by inhibiting glucuronidation by endogenous glucuronosyltransferase, which results in depletion of uridine diphosphate glucuronic acid [7]. 4-MU also downregulates HAS2 and HAS3 expression [12]. Recent studies showed that 4-MU had an antitumor effect on prostate, breast, and hepatocellular carcinomas through the inhibition of HA synthesis [13-15]. Therefore, the CD44-HA interaction may be a promising target for therapeutic intervention of metastases. However, the clinical implications of 4-MU administration and ovarian cancer growth have not been investigated.

This study was conducted to investigate the antitumor potential of 4-MU against human ovarian cancer cells and to elucidate its mechanism of action.

\section{Methods}

\section{Chemicals and cell culture}

4-MU was purchased from Tokyo Chemical Industry (Tokyo, Japan). HRA cells, which were derived from a human ovarian serous adenocarcinoma [16], were kindly provided by Dr. Y. Kikuchi (National Defense Medical College, Japan) and were maintained in RPMI 1640 medium (Invitrogen, Tokyo, Japan) supplemented with $10 \%$ fetal bovine serum (FBS), $100 \mathrm{U} / \mathrm{ml}$ penicillin, and $100 \mu \mathrm{g} / \mathrm{ml}$ streptomycin at $37^{\circ} \mathrm{C}$ in a humidified atmosphere with $5 \% \mathrm{CO}_{2} / 95 \%$ air. This cell line was authenticated as being ovarian in origin with a written guarantee. 4-MU stock solution for in vitro experiments was dissolved in medium containing $1 \%$ dimethylsulfoxide (DMSO) (Sigma-Aldrich, St Louis, MO) and the final concentration of DMSO in the medium was adjusted to $0.1 \%$.

\section{Ethics statement}

Animal experiments were approved by the Animal Research Committee of Hirosaki University (M13024) and all animals were cared for and handled in accordance to the Rules for Animal Experimentation of Hirosaki University and animal practices as defined by the national and local animal welfare bodies (Guide for the Care and Use of Laboratory Animals published by the National Institutes of Health). Animals were sacrificed according to the Guidelines for Euthanasia of Rodents using carbon dioxide.

\section{Peritoneal carcinomatosis model}

Eight-week-old female F344/NJcl-rnu/rnu nude rats (CLEA Japan, Inc., Tokyo, Japan) were used in this study. Rats were group-housed in plastic cages with stainlesssteel grid tops under a 12-hour light/dark cycle and given free access to water and food. Laparotomy was performed under sterile conditions and with general anesthesia using pentobarbital. Anesthesia was maintained up to 30 minutes with good analgesia and muscle relaxation. The omentum was accessed via a $4-\mathrm{cm}$ midline incision in the abdomen and subsequently extirpated by ligating the gastroepiploic vessels and hilum of the spleen [17]. After hemostasis, the abdominal wall was closed in 2 layers by using $3 / 0$ polyglactin (Vicryl ${ }^{\circledR}$, Ethicon, Tokyo, Japan). No animals died as a result of the operative procedure. On the second day after surgery, HRA cells $\left(3.7 \times 10^{7}\right.$ cells $)$ were inoculated into the peritoneal cavity of the rats by injecting cells intraperitoneally with a 22-gauge needle. The rats were divided into 2 groups $(\mathrm{n}=5$ each). In the 4 -MU-treated group, rats were administered 4-MU (100 mg per body) dissolved in $2.0 \mathrm{ml}$ of $0.4 \%$ carboxymethylcellulose (CMC) solution (Sigma-Aldrich) intraperitoneally daily starting on the day when the cells were inoculated. The same volume of 0.4\% CMC solution without 4-MU was administered intrapetitoneally to the rats in the control group. We allowed a subset of animals from each group to survive until the humane endpoints defined by inability to access food or water or increased effort due to progressing abdominal ascites. Rats were sacrificed by carbon oxide asphyxiation at the defined humane endpoints. Their health conditions were observed daily and all efforts were made to minimize suffering.

\section{Cell proliferation assay}

Cell proliferation was assayed by using a Cell Counting Kit-8 (CCK-8; Dojin Laboratories, Kumamoto, Japan). HRA cells were cultured overnight in 96-well microplates at $2 \times 10^{3}$ cells per well with $100 \mu \mathrm{l}$ of medium. Further, the cells were treated with $0,0.2,0.6$, and $1.0 \mathrm{mM}$ 4-MU and cultured for 72 hours. Cell viability was assessed 3 hours after the addition of CCK- 8 by measuring $\mathrm{A}_{450}$ with a Multiskan FC microplate reader (Thermo scientific, Yokohama, Japan). A preliminary study using this kit showed that absorbance was directly 
proportional to the number of cells. The experiment was conducted 5 times.

\section{Cell invasion and migration assay}

Cell invasion and migration were assessed with a Cytoselect Cell Invasion Assay (Cell Biolabs, Inc., San Diego, CA) and a Cytoselect Cell Migration Assay (Cell Biolabs, Inc.), respectively, according to the manufacturer's protocol. For invasion assays, HRA cells $\left(1.0 \times 10^{5}\right.$ cells per well) in serum-free medium containing $0,0.2,0.6$, or $1.0 \mathrm{mM} 4-\mathrm{MU}$ were placed in the upper chamber, which had an $8.0-\mu \mathrm{m}$ pore size membrane coated with a uniform layer of basement membrane matrix solution, and medium with $10 \%$ FBS was placed in the lower chamber. After 24 hours, the cells from the underside of the membrane were removed by tilting the membrane chamber in Cell Detachment Solution. Lysis Buffer/CyQUANT GR dye solution was added to each well and the fluorescence of the mixture was measured by using a fluorescence plate reader (Fluoroskan Ascent, Thermo Scientific) at excitation and emission wavelengths of $480 \mathrm{~nm}$ and $520 \mathrm{~nm}$, respectively. For migration assays, HRA cells $\left(1.0 \times 10^{5}\right.$ cells per well $)$ in serum-free medium containing $0,0.2,0.6$, or $1.0 \mathrm{mM} \mathrm{4-MU}$ were placed in the upper chamber, which had an $8.0-\mu \mathrm{m}$ pore size membrane without basement membrane matrix solution, and medium with $10 \%$ FBS was placed in the lower chamber. After 3 hours, the cells that had migrated to the lower surface were quantified by using CyQUANT GR dye as described above. Each experiment was performed in triplicate.

Real-time quantitative polymerase chain reaction (qPCR) Expression levels of HAS2, HAS3, CD44, vascular endothelial growth factor (VEGF), and thymidine phosphorylase (TP) were determined in HRA cells cultured with or without $1.0 \mathrm{mM}$ 4-MU for 24 hours. Total RNA was extracted from the cells by using an Illustra RNAspin Mini RNA Isolation Kit (GE Healthcare, Piscataway, NJ) and cDNA was synthesized with an iScript Advanced cDNA Synthesis Kit (Bio-Rad, Hercules, CA). Real-time qPCR was performed by using a CFX96 real-time PCR detection system (Bio-Rad) and a SsoAdvanced SYBR Green Supermix solution (Bio-Rad), according to the manufacturer's specifications. The amplification conditions were as follows: 30 seconds at $95^{\circ} \mathrm{C}$, followed by $95^{\circ} \mathrm{C}$ for 5 seconds and $60^{\circ} \mathrm{C}$ for 30 seconds for 40 consecutive cycles. After amplification, a melting curve from $65^{\circ} \mathrm{C}$ to $95^{\circ} \mathrm{C}$ at $0.5^{\circ} \mathrm{C}$ increments and 5 seconds per step was generated with continuous monitoring of fluorescence. The melting curves and quantitative analysis of the data were performed by using CFX manager Version 2.1 software (Bio-Rad). The mRNA levels of HAS2, HAS3, CD44, TP, and VEGF in a sample were normalized to the amount of $18 \mathrm{~S}$ rRNA [18]. The sequences of the primers were as follows:

HAS2 forward, 5' -CAGCCTCATCTGTGGAGATGG TAA-3'

HAS2 reverse, 5' -CCAGAGGTCCACTAATGCACTG AA-3'

HAS3 forward, 5' -TGCGACTCTGACACTGTGCTG-3'

HAS3 reverse, 5' -GGAAATCCATGAGTCGTACTTG TTG-3'

CD44 forward, 5' -CTCCGGACACCATGGACAA-3'

CD44 reverse, 5' -CCACGTGGAATACACCTGCAA-3'

TP forward, 5' -GGCTGCTGTATCGTGGGTCA-3'

TP reverse, 5' -GAACTTAACGTCCACCACCAGAG-3'

VEGF forward, 5' -TGGAGTGTGTGCCCACTGAG-3'

VEGF reverse, $5^{\prime}$ - TGCATTCACATTTGTTGTGCTGT AG-3'

18S rRNA forward, 5' -ACTCAACACGGGAAACCTCA-3' $18 \mathrm{~S}$ rRNA reverse, 5' -AACCAGACAAATCGCTCCAC-3' Specific primer sets for HAS2, HAS3, CD44, VEGF, and TP were purchased from Takara Bio, Inc. (Otsu, Japan). 18S rRNA specific primers were purchased from FASMAC (Atsugi, Japan).

\section{Western blot analysis}

Cell lysates (50 $\mu \mathrm{g}$ protein) were prepared from cultured HRA cells treated with $0,0.2,0.6$, and $1.0 \mathrm{mM} 4-\mathrm{MU}$ for 72 hours, electrophoresed through a $12.5 \%$ sodium dodecyl sulfate polyacrylamide gel, and blotted as described previously [19]. The protein concentration was determined using Bradford's method. The blots were probed with the following diluted antibodies for 2 hours: TP (Proteintech, Chicago, IL) (Catalog number: 12383-1AP) at 1:1000 and $\beta$-actin (Sigma-Aldrich) at 1:2000. The membranes were then incubated for 1 hour with the appropriate biotinylated secondary antibodies, transferred to avidin-biotin-peroxidase complex reagent, and incubated in this solution for 30 minutes. Diaminobenzidine was used as a substrate.

\section{Statistical analysis}

Survival rates were calculated by using the Kaplan-Meier method and the statistical significance of differences in the cumulative survival curves between the groups was evaluated using the Wilcoxon test. Other statistical analyses were carried out with Student's $t$-test. $P$ values $<0.05$ were considered statistically significant.

\section{Results}

Anti-tumor effect of 4-MU in a peritonitis carcinomatosa model

The survival periods of the control and 4-MU-treated groups were compared. All rats in the control group died by day 13. 4-MU administration in the 4-MUtreated group was discontinued after day 14 and survival 
was monitored thereafter for another 3 weeks. The survival times were significantly longer in the 4-MU-treated group than in the control group $(P<0.05$, Figure $1 \mathrm{~A})$. Hemorrhagic ascites developed in the control group, whereas they were absent or mild in the 4-MU-treated group. Therefore, there was significant difference in body weight gain between the 2 groups (Figure 1B). As shown in Figure $1 \mathrm{C}$, peritoneal tumors developed in the control group. Two rats in the 4-MU-treated group survived for 5 weeks and were sacrificed with carbon dioxide as described in Ethics statement section, although they reached the defined humane endpoints at the experimental endpoint. The post-mortem examination showed that their intraperitoneal tumors were much smaller than those in the control rats even though 4-MU administration was discontinued after day 14 (Figure 1C). Neither pleural effusion nor pleural metastasis was observed in both groups.

Effects of 4-MU on cell proliferation, invasion, and migration Figure 2A shows cell viability assessed by measuring $\mathrm{A}_{450}$ with a Multiskan FC microplate reader 3 hours after the addition of CCK-8. The cell viability of control cells had increased approximately 4-fold between 24 and 72 hours after plating, while proliferation of cells treated with 0.2 , 0.6 , or $1.0 \mathrm{mM} 4-\mathrm{MU}$ decreased over time, suggesting that 4-MU significantly inhibited the proliferation of HRA cells in a dose-dependent manner. However, 4-MU treatment did not affect cell invasion or migration (Figure $2 \mathrm{~B}$ and $\mathrm{C}$ ).

\section{Altered TP protein and mRNA expression levels in HRA cells treated with 4-MU}

Western blot analysis showed that 4-MU reduced TP protein level in a dose-dependent manner (Figure 3A). Realtime quantitative PCR confirmed a significant reduction of TP mRNA expression level in HRA cells treated with $1.0 \mathrm{mM}$ 4-MU, whereas no significant difference in HAS3 expression was observed between HRA cells cultured with and without 4-MU (Figure 3B). Since HAS2, CD44, and VEGF endogenous mRNA expression levels were very low in HRA cells although their expression levels were high in U373MG human astrocytoma cells [18] and SH-SY5Y human neuroblastoma cells [20], it was impossible to evaluate the effect of 4-MU treatment (data not shown).

\section{Discussion}

Survival was significantly prolonged by the administration of 4-MU to rats with peritonitis carcinomatosa
A

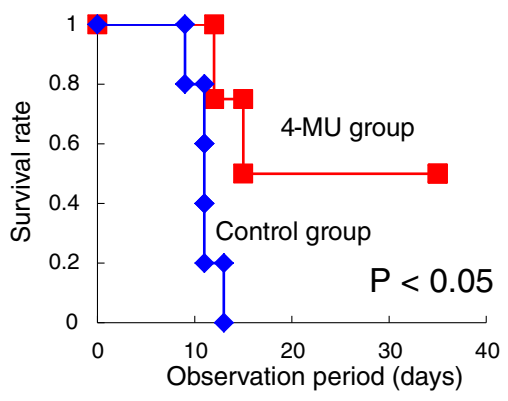

B
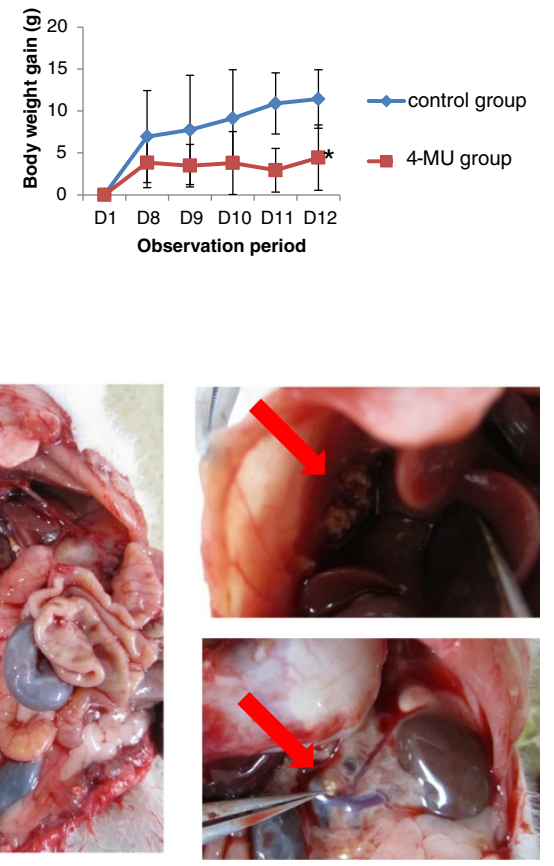

4-MU group

Figure 1 Anti-tumor effect of 4-MU in a peritonitis carcinomatosa model. (A) Rats in the control group did not survive after day 13. The survival times were significantly prolonged in the 4-MU-treated group compared with the control group $(P<0.05)$. (B) There was a significant difference in body weight gain between the 2 groups due to increased malignant ascites. ${ }^{*} P<0.05$ (C) Differences in peritoneal tumors between the 2 groups. Rats in the control group developed large peritoneal tumors, whereas tumor sizes were smaller in rats in the 4-MU-treated group. The arrows indicate peritoneal tumors. 


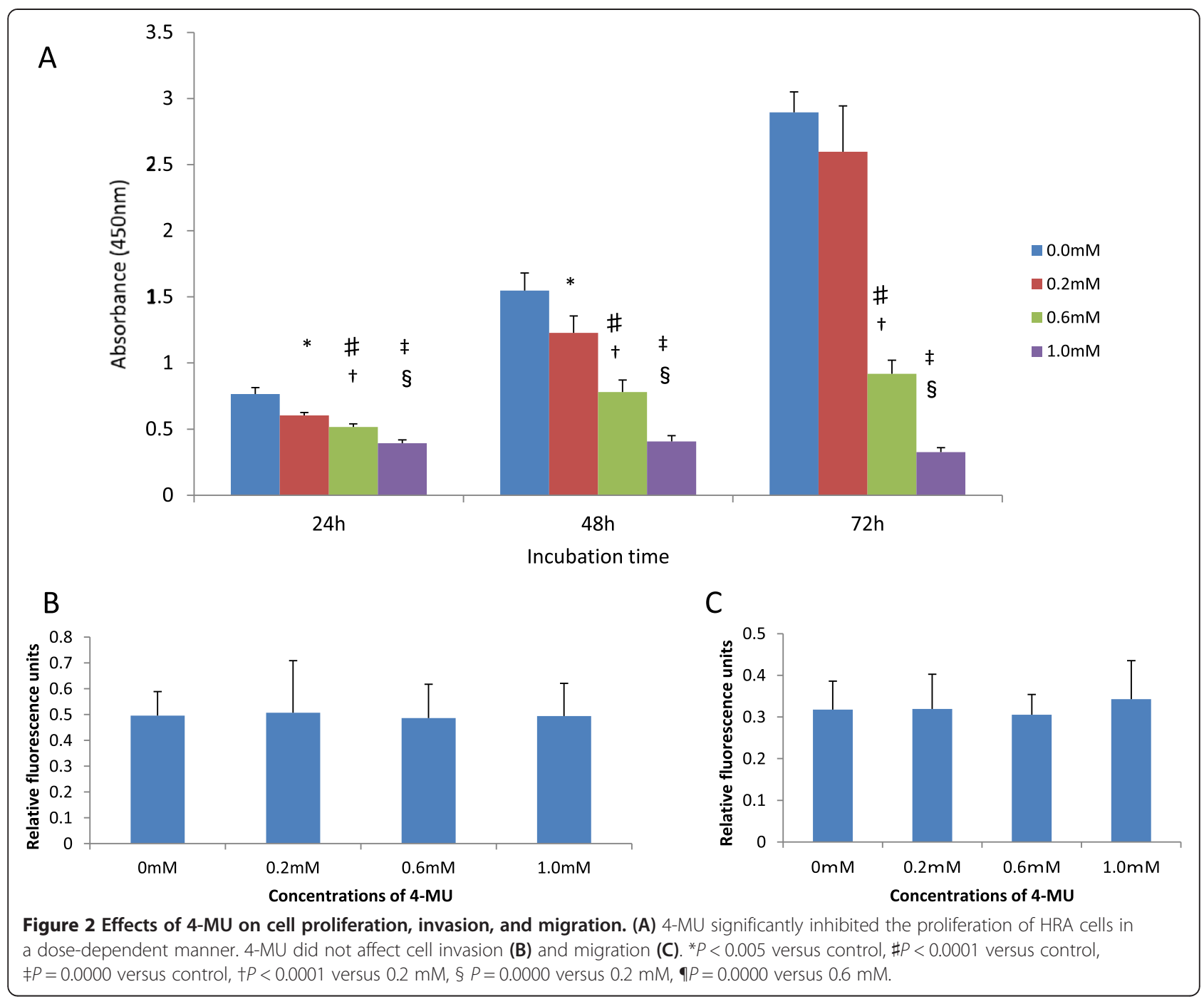

resulting from inoculation with HRA cells. 4-MU also showed potential for reducing peritoneal dissemination of tumors as well as malignant ascites production. Rats were not administered 4-MU after day 14; however, the effect lasted until the end of the experiment. Although the rats that survived for 5 weeks had small peritoneal masses, there were no malignant ascites in their abdomen, suggesting that 4-MU treatment inhibits implantation and proliferation of malignant cells in these animals. Because 3 of the 4-MU-treated rats died of peritonitis carcinomatosa by day 13 , technical aspects such as administration route and optimal dose of 4-MU must be reconsidered.

In the in vitro experiments, 4-MU inhibited proliferation of HRA cells in a dose-dependent manner, supporting previous results obtained in other types of cancer cells $[13-15,21,22]$. Although previous studies showed that 4-MU inhibited cancer growth by inhibiting cell invasion and migration $[11,12,22]$, the present study did not show an effect of 4-MU on HRA cell invasion and migration. Although counting the number of cells that moved to lower membrane by staining with hematoxylin might be more appropriate in order to detect a little difference, this discrepancy may be partly accounted for by the absence of CD44 receptors on the surface of HRA cells. 4-MU is shown to elicit its action through inhibiting HAS that plays an important role in tumor growth via binding to CD44 receptors located on surface of cancer cells. Moreover, Day and Prestwich [23] suggested the existence of other receptors, indicating that 4-MU might exert its anti-proliferative effect directly or via an unknown receptor.

The antitumor mechanism of 4-MU remains poorly understood. HA, which is a high-molecular-weight glycosaminoglycan and a major component of extracellular matrix, promotes tumor proliferation, invasion, and migration by binding to the CD44 HA receptor [24]. HA is produced by HAS1, HAS2, and HAS3. Ovarian serous 

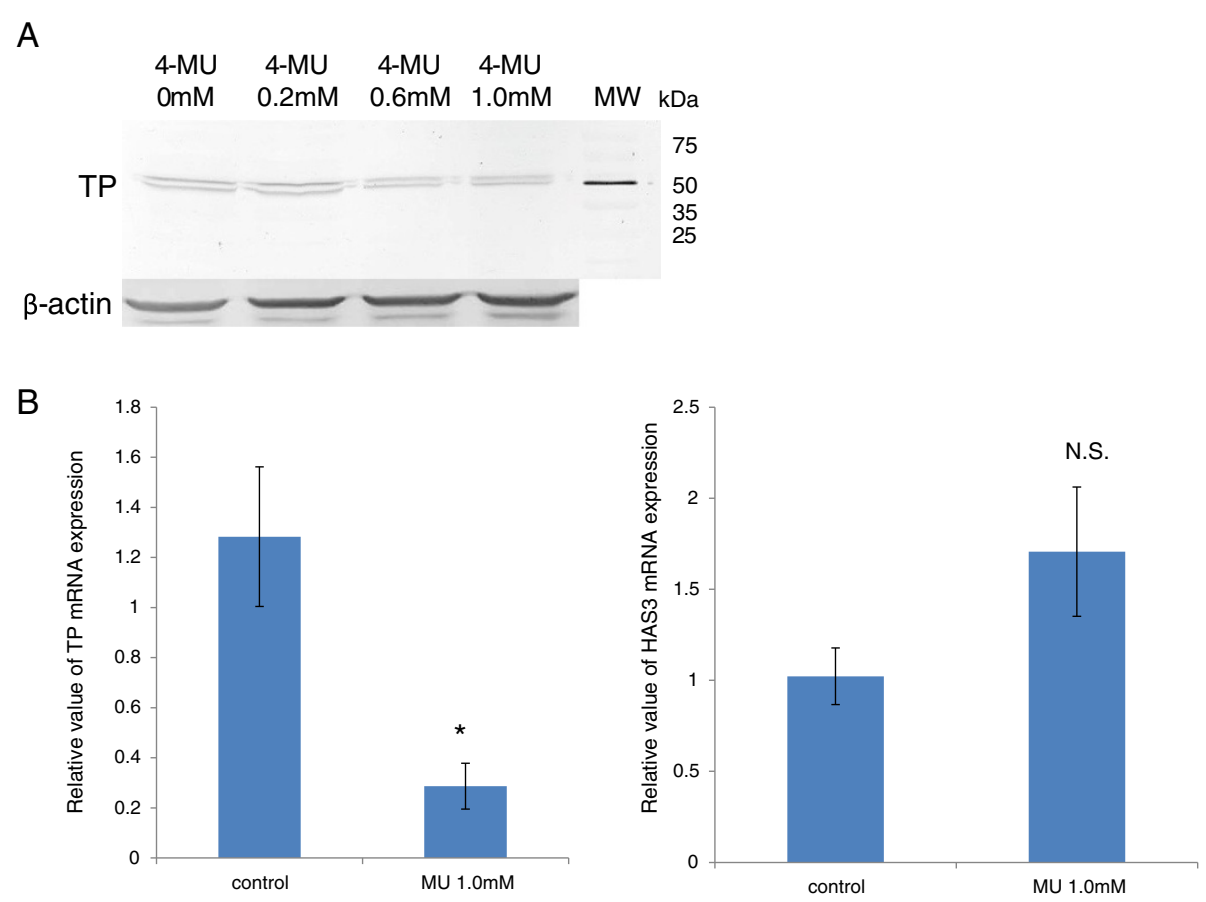

Figure 3 4-MU treatment altered TP protein and mRNA expression levels in HRA cells. (A) Western blot showed a reduction of TP protein in a dose-dependent manner of 4-MU. MW abbreviated molecular weight. (B) 4-MU administration significantly reduced the TP mRNA expression level in HRA cells (left panel), whereas there was no significant difference in HAS3 expression between HRA cells cultured with and without 4-MU (right panel). The relative expression of TP and HAS3 mRNA was analyzed by qRT-PCR in HRA cells cultured with or without $1.0 \mathrm{mM} 4-\mathrm{MU}$ for 24 hours. The data presented are the average \pm SD of the relative mRNA expression values normalized to the $18 \mathrm{~S}$ rRNA amount (*indicates $P=0.0005$ compared with control).

adenocarcinomas express HAS2 and HAS3 [25], and Anttila et al. [26] reported that high levels of stromal HA predict poor prognosis in patients with epithelial ovarian cancer. It is known that the HA-CD44 interaction can lead to the activation of intracellular signaling pathways such as PI3K/Akt that affect the proliferation, migration, and invasion of cancer cells [27]. Recently, CD44 was shown to be a cancer stem cell marker [10], and it was reported that CD44 could promote cell motility and tumorigenicity [11]. Earlier studies suggested that 4-MU exerted its antitumor activity by downregulating HAS and CD44 mRNA levels, leading to inhibition of HA synthesis as well as HA-CD44 binding [13]. However, this study revealed that HRA cells expressed extremely low levels of HAS2 and CD44 mRNA and that the expression level of HAS3 mRNA in HRA cells was low and was not altered by 4-MU administration, so HA production was not determined in this study. These results suggest that the anti-tumor effect of $M U$ is dependent on a mechanism other than HA-CD44 signaling. Since hepatocellular carcinoma (HCC) generally arises in a cirrhotic liver, it is important to investigate HCC development in association with a fibrotic microenvironment [15]. 4-MU has anti-fibrogenic activity. Piccioni et al. [15] reported that 4-MU might be an anti- cancer agent for HCC associated with advanced fibrosis because it induced apoptosis of hepatic stellate cells (HSCs), which play a key role in advancing liver fibrosis, and decreased the number of activated HSCs. Saito et al. also reported that 4-MU inhibited cell proliferation and induced apoptosis in breast cancer cells together with inhibiting HA synthesis accompanied by downregulation of HAS2 mRNA levels in a dose-depending manner [28]. Therefore, 4-MU may have different anti-tumor mechanisms depending on the type of cancer.

It is well known that progression and metastasis of ovarian cancer are largely attributable to the activity of different angiogenic factors $[29,30]$ and that the main route of development of this disease is via peritoneal dissemination with malignant ascites [19]. A recent study indicated that 4-MU inhibited angiogenesis in vitro and in vivo [31]. Thus, we determined the expression levels of VEGF and TP in HRA cells cultured with or without 4-MU. VEGF is a multifunctional cytokine and it is well known as an angiogenic factor [32]. Bevacizumab, a monoclonal antibody against VEGF, is used clinically as a treatment for ovarian cancer [3]. TP catalyzes the reversible phospholysis of thymidine, deoxyuridine, and their analogs to their respective bases and 2-deoxyribose-1-phosphate [33]. TP is identical to platelet-derived endothelial cell growth factor and has 
angiogenic factor activity [34]. Its expression in ovarian cancer patients is associated with a poor prognosis [35]. Tsukagoshi et al. [36] reported that angiogenesis in ovarian serous adenocarcinoma cell lines, including HRA, is dependent on TP mRNA expression and treatment with a TP inhibitor could block angiogenesis in those cell lines. Recently, some studies suggested that TP has an antiapoptosis activity in addition to its angiogenic activity $[37,38]$. The present study showed that although HRA cells did not express VEGF mRNA, TP mRNA expression was significantly decreased by 4-MU treatment, suggesting that decreased TP expression may be involved in the inhibitory effect of 4-MU on ovarian cancer. Ko et al. [39] reported that PI3K/Akt signaling regulated TP expression. Therefore, 4-MU might inactivate PI3K/Akt signaling by suppressing a ligand-receptor interaction different from the HA-CD44 interaction.

To our knowledge, this is the first study to report an inhibitory effect of 4-MU on ovarian cancer. Although earlier studies showed that 4-MU exhibited its antitumor activity by suppressing the HA-CD44 interaction, this study demonstrated that 4-MU downregulated TP expression in ovarian cancer cells. This suggests that 4-MU may act as an angiogenesis inhibitor and have potential as a new drug in the therapeutic strategy for ovarian cancer.

\section{Competing interests}

The authors declare that they have no competing interests.

\section{Authors' contributions}

RT participated in the design of the study, acquired the data, interpreted the data, preformed all of in vitro and in vivo experiments, and wrote the manuscript. YY participated in the design of the study, interpreted the data, and performed the statistical analysis. HY performed RT-PCR experiment and interpreted the data. TI performed RT-PCR experiment and interpreted the data. HM participated in the design of the study, interpreted the data, and performed the statistical analysis. All authors participated in the preparation of the manuscript as well as reviewed and approved the final manuscript.

\section{Acknowledgement}

This study was supported by a Grant-in Aid for Cancer Research (No. 20591935) from the Ministry of Education, Science and Culture of Japan.

\section{Author details}

${ }^{1}$ Department of Obstetrics and Gynecology, Hirosaki University Graduate School of Medicine, 5 Zaifu-cho, Hirosaki 036-8562, Japan. ${ }^{2}$ Department of Vascular Biology, Institute of Brain Science, Hirosaki University Graduate School of Medicine, 5 Zaifu-cho, Hirosaki 036-8562, Japan.

Received: 16 August 2014 Accepted: 1 October 2014

Published online: 11 October 2014

\section{References}

1. Jemal A, Bray F, Center MM, Ferlay J, Ward E, Forman D: Global cancer statistics. CA Cancer J Clin 2011, 61(2):69-90.

2. Ozols RF, Bundy BN, Greer BE, Fowler JM, Clarke-Pearson D, Burger RA, Mannel RS, DeGeest K, Hartenbach EM, Baergen R: Phase III trial of carboplatin and paclitaxel compared with cisplatin and paclitaxel in patients with optimally resected stage III ovarian cancer: a gynecologic oncology group study. J Clin Oncol 2003, 21(17):3194-3200.

3. Burger RA, Brady MF, Bookman MA, Fleming GF, Monk BJ, Huang H, Mannel RS, Homesley HD, Fowler J, Greer BE, Boente M, Birrer MJ, Liang SX:
Incorporation of bevacizumab in the primary treatment of ovarian cancer. N Engl J Med 2011, 365(26):2473-2483.

4. Ledermann J, Harter P, Gourley C, Friedlander M, Vergote I, Rustin G, Scott C, Meier W, Shapira-Frommer R, Safra T, Matei D, Macpherson E, Watkins C, Carmichael J, Matulonis U: Olaparib maintenance therapy in platinum-sensitive relapsed ovarian cancer. N Engl J Med 2012, 366(15):1382-1392.

5. Armstrong DK, White AJ, Weil SC, Phillips M, Coleman RL: Farletuzumab (a monoclonal antibody against folate receptor alpha) in relapsed platinum-sensitive ovarian cancer. Gynecol Oncol 2013, 129(3):452-458.

6. Monk BJ, Herzog TJ, Kaye SB, Krasner CN, Vermorken JB, Muggia FM, Pujade-Lauraine E, Lisyanskaya AS, Makhson AN, Rolski J, Gorbounova VA, Ghatage P, Bidzinski M, Shen K, Ngan HY, Vergote IB, Nam JH, Park YC, Lebedinsky CA, Poveda AM: Trabectedin plus pegylated liposomal doxorubicin in recurrent ovarian cancer. J Clin Oncol 2010, 28(19):3107-3114.

7. Kakizaki I, Kojima K, Takagaki K, Endo M, Kannagi R, Ito M, Maruo Y, Sato H, Yasuda T, Mita S, Kimata K, Itano N: A novel mechanism for the inhibition of hyaluronan biosynthesis by 4-methylumbelliferone. J Biol Chem 2004, 279(32):33281-33289.

8. Miyake K, Underhill CB, Lesley J, Kincade PW: Hyaluronate can function as a cell adhesion molecule and CD44 participates in hyaluronate recognition. J Exp Med 1990, 172(1):69-75.

9. Bourguignon LY, Spevak CC, Wong G, Xia W, Gilad E: Hyaluronan-CD44 interaction with protein kinase $C$ (epsilon) promotes oncogenic signaling by the stem cell marker Nanog and the Production of microRNA-21, leading to down-regulation of the tumor suppressor protein PDCD4, anti-apoptosis, and chemotherapy resistance in breast tumor cells. J Biol Chem 2009, 284(39):26533-26546.

10. Bourguignon LY, Wong G, Earle $C$, Chen L: Hyaluronan-CD44v3 interaction with Oct4-Sox2-Nanog promotes miR-302 expression leading to self-renewal, clonal formation, and cisplatin resistance in cancer stem cells from head and neck squamous cell carcinoma. J Biol Chem 2012, 287(39):32800-32824.

11. Hiraga T, Ito S, Nakamura H: Cancer stem-like cell marker CD44 promotes bone metastases by enhancing tumorigenicity, cell motility, and hyaluronan production. Cancer Res 2013, 73(13):4112-4122.

12. Kultti A, Pasonen-Seppänen $S$, Jauhiainen M, Rilla KJ, Kärnä R, Pyöriä E, Tammi RH, Tammi Ml: 4-Methylumbelliferone inhibits hyaluronan synthesis by depletion of cellular UDP-glucuronic acid and downregulation of hyaluronan synthase 2 and 3. Exp Cell Res 2009, 315(11):1914-1923.

13. Lokeshwar VB, Lopez LE, Munoz D, Chi A, Shirodkar SP, Lokeshwar SD, Escudero DO, Dhir N, Altman N: Antitumor activity of hyaluronic acid synthesis inhibitor 4-methylumbelliferone in prostate cancer cells. Cancer Res 2010, 70(7):2613-2623.

14. Urakawa H, Nishida Y, Wasa J, Arai E, Zhuo L, Kimata K, Kozawa E, Futamura $\mathrm{N}$, Ishiguro $\mathrm{N}$ : Inhibition of hyaluronan synthesis in breast cancer cells by 4-methylumbelliferone suppresses tumorigenicity in vitro and metastatic lesions of bone in vivo. Int J Cancer 2012, 130(2):454-466.

15. Piccioni F, Malvicini M, Garcia MG, Rodriguez A, Atorrasagasti C, Kippes N, Piedra Buena IT, Rizzo MM, Bayo J, Aquino J, Viola M, Passi A, Alaniz L, Mazzolini $\mathrm{G}$ : Antitumor effects of hyaluronic acid inhibitor 4-methylumbelliferone in an orthotopic hepatocellular carcinoma model in mice. Glycobiology 2012, 22(3):400-410.

16. Kikuchi Y, Kizawa I, Oomori K, Miyauchi M, Kita T, Sugita M, Tenjin Y, Kato K: Establishment of a human ovarian cancer cell line capable of forming ascites in nude mice and effects of tranexamic acid on cell proliferation and ascites formation. Cancer Res 1987, 47(2):592-596.

17. Yokoyama $\mathrm{Y}$, Hirakawa $\mathrm{H}$, Wang H, Mizunuma H: Is omentectomy mandatory in the operation for ovarian cancer? Eur J Obstet Gynecol Reprod Biol 2012, 164(1):89-92.

18. Yoshida H, Meng P, Matsumiya T, Tanji K, Hayakari R, Xing F, Wang L, Tsuruga K, Tanaka H, Mimura J, Kosaka K, Itoh K, Takahashi I, Imaizumi T: Carnosic acid suppresses the production of amyloid- $\beta$ 1-42 and 1-43 by inducing an a-secretase TACE/ADAM17 in U373MG human astrocytoma cells. Neurosci Res 2014, 79:83-93. doi:10.1016/j.neures.2013.11.004.

19. Yokoyama Y, Xin B, Shigeto T, Umemoto M, Kasai-Sakamoto A, Futagami M, Tsuchida S, Al-Mulla F, Mizunuma H: Clofibric acid, a peroxisome proliferator-activated receptor alpha ligand, inhibits growth of human ovarian cancer. Mol Cancer Ther 2007, 6(4):1379-1386.

20. Meng P, Yoshida H, Matsumiya T, Imaizumi T, Tanji K, Xing F, Hayakari R, Dempoya J, Tatsuta T, Aizawa-Yashiro T, Mimura J, Kosaka K, Itoh K, Satoh K: Carnosic acid suppresses the production of amyloid- $\beta$ 1-42 by inducing the metalloprotease gene TACE/ADAM17 in SH-SY5Y human neuroblastoma cells. Neurosci Res 2013, 75:94-102. doi:10.1016/j.neures.2012.11.007. 
21. Yoshihara S, Kon A, Kudo D, Nakazawa H, Kakizaki I, Sasaki M, Endo M, Takagaki K: A hyaluronan synthase suppressor, 4-methylumbelliferone, inhibits liver metastasis of melanoma cells. FEBS Lett 2005, 579(12):2722-2726.

22. Arai E, Nishida Y, Wasa J, Urakawa H, Zhuo L, Kimata K, Kozawa E, Futamura N, Ishiguro N: Inhibition of hyaluronan retention by 4-methylumbelliferone suppresses osteosarcoma cells in vitro and lung metastasis in vivo. Br J Cancer 2011, 105(12):1839-1849.

23. Day AJ, Prestwich GD: Hyaluronan-binding proteins: tying up the giant. J Biol Chem 2002, 277(7):4585-4588.

24. Ponta H, Sherman L, Herrlich PA: CD44: from adhesion molecules to signalling regulators. Nat Rev Mol Cell Biol 2003, 4(1):33-45.

25. Nykopp TK, Rilla K, Sironen R, Tammi MI, Tammi RH, Hämäläinen K, Heikkinen AM, Komulainen M, Kosma VM, Anttila M: Expression of hyaluronan synthases (HAS1-3) and hyaluronidases (HYAL1-2) in serous ovarian carcinomas: inverse correlation between HYAL1 and hyaluronan content. BMC Cancer 2009, 9:143. doi:10.1186/1471-2407-9-143.

26. Anttila MA, Tammi RH, Tammi MI, Syrjänen KJ, Saarikoski SV, Kosma VM: High levels of stromal hyaluronan predict poor disease outcome in epithelial ovarian cancer. Cancer Res 2000, 60(1):150-155.

27. Sohara Y, Ishiguro N, Machida K, Kurata H, Thant AA, Senga T, Matsuda S, Kimata K, Iwata $\mathrm{H}$, Hamaguchi M: Hyaluronan activates cell motility of v-Src-transformed cells via Ras-mitogen-activated protein kinase and phosphoinositide 3-kinase-Akt in a tumor-specific manner. Mol Biol Cell 2001, 12(6):1859-1868.

28. Saito T, Tamura D, Nakamura T, Makita Y, Ariyama H, Komiyama K, Yoshihara T, Asano R: 4-methylumbelliferone leads to growth arrest and apoptosis in canine mammary tumor cells. Oncol Rep 2013, 29(1):335-342.

29. Yoneda J, Kuniyasu H, Crispens MA, Price JE, Bucana CD, Fidler IJ: Expression of angiogenesis-related genes and progression of human ovarian carcinomas in nude mice. J Natl Cancer Inst 1998, 90(6):447-454.

30. Yokoyama Y, Charnock-Jones DS, Licence D, Yanaihara A, Hastings JM, Holland CM, Emoto M, Umemoto M, Sakamoto T, Sato S, Mizunuma H, Smith SK: Vascular endothelial growth factor-D is an independent prognostic factor in epithelial ovarian carcinoma. Br J Cancer 2003, 88(2):237-244.

31. García-Vilas JA, Quesada AR, Medina MÁ: 4-methylumbelliferone inhibits angiogenesis in vitro and in vivo. J Agric Food Chem 2013, 61(17):4063-4071.

32. Cao Y, Linden P, Shima D, Browne F, Folkman J: In vivo angiogenic activity and hypoxia induction of heterodimers of placenta growth factor/ vascular endothelial growth factor. J Clin Invest 1996, 98(11):2507-2511.

33. de Bruin M, Smid K, Laan AC, Noordhuis P, Fukushima M, Hoekman K, Pinedo HM, Peters GJ: Rapid disappearance of deoxyribose-1-phosphate in platelet derived endothelial cell growth factor/thymidine phosphorylase overexpressing cells. Biochem Biophys Res Commun 2003, 301(3):675-679.

34. Folkman J: What is the role of thymidine phosphorylase in tumor angiogenesis. J Natl Cancer Inst 1996, 88(16):1091-1092.

35. Fujiwaki R, Hata K, Nakayama K, Fukumoto M, Miyazaki K: Thymidylatesynthase expression in epithelial ovarian cancer: relationship with thymidine phosphorylase expression and prognosis. Oncology 2000, 59(2):152-157.

36. Tsukagoshi S, Saga Y, Suzuki N, Fujioka A, Nakagawa F, Fukushima M, Suzuki M: Thymidine phosphorylase-mediated angiogenesis regulated by thymidine phosphorylase inhibitor in human ovarian cancer cells in vivo. Int J Oncol 2003, 22(5):961-967.

37. Kitazono M, Takebayashi Y, Ishitsuka K, Takao S, Tani A, Furukawa T, Miyadera K, Yamada Y, Aikou T, Akiyama S: Prevention of hypoxia-induced poptosis by the angiogenic factor thymidine phosphorylase. Biochem Biophys Res Commun 1998, 253(3):797-803.

38. Jeung HC, Che XF, Haraguchi M, Furukawa T, Zheng CL, Sumizawa T, Rha SY, Roh JK, Akiyama S: Thymidine phosphorylase suppresses apoptosis induced by microtubule-interfering agents. Biochem Pharmacol 2005, 70(1):13-21.

39. Ko JC, Chiu HC, Syu JJ, Jian YJ, Chen CY, Jian YT, Huang YJ, Wo TY, Lin YW: Tamoxifen enhances erlotinib-induced cytotoxicity through down-regulating AKT-mediated thymidine phosphorylase expression in human non-small-cell lung cancer cells. Biochem Pharmacol 2014, 88(1):119-127.

doi:10.1186/s13048-014-0094-2

Cite this article as: Tamura et al:: 4-Methylumbelliferone inhibits ovarian cancer growth by suppressing thymidine phosphorylase expression. Journal of Ovarian Research 2014 7:94.

\section{Submit your next manuscript to BioMed Central and take full advantage of:}

- Convenient online submission

- Thorough peer review

- No space constraints or color figure charges

- Immediate publication on acceptance

- Inclusion in PubMed, CAS, Scopus and Google Scholar

- Research which is freely available for redistribution 